\title{
Letter
}

\section{Addition of granulocyte-colony stimulating factor (G-CSF) may further increase chemosensitive state in premenopausal node- positive breast cancer patients with induced angiogenesis after surgery}

\author{
Kadri Altundag ${ }^{1}$, Ozden Altundag ${ }^{1}$ and Mehmet Gunduz ${ }^{2}$ \\ ${ }^{1}$ Department of Medical Oncology, Hacettepe University Faculty of Medicine, Ankara, Turkey \\ 2Department of Oral Pathology and Medicine, Graduate School of Medicine and Dentistry, Okayama University, Okayama, Japan \\ Corresponding author: Kadri Altundag, e-mail: drkadri@usa.net \\ Published: 15 June 2004
}

Breast Cancer Res 2004, 6:E14 (DOI 10.1186/bcr903)

(C) 2004 BioMed Central Ltd

See related research article by Retsky et al., http://breast-cancer-research.com/content/6/4/R372,

and related commentary by Baum, http://breast-cancer-research.com/content/6/4/160

We read with great interest the article by Retsky and colleagues in this issue of Breast Cancer Research [1]. They hypothesize that there is induced angiogenesis after breast cancer surgery in approximately $20 \%$ of premenopausal node-positive patients, which stimulates division of dormant micrometastatic cells and synchronizes them into a highly chemosensitive state. Therefore, adjuvant chemotherapy works particularly well for that patient category. Breast cancer stem cells in the thousands of micrometastatic cancer cells have the capacity to repopulate and metastasize. Granulocytecolony stimulating factor (G-CSF) stimulates the pluripotent stem cell and neutrophil precursors to divide and increase the production of mature neutrophils, thus enhancing the function of mature neutrophils, which ameliorates neutropenia and the associated complications. These breast cancer stem cells have not been totally characterized, and may carry antigens almost identical to those carried by hematopoietic stem cells [2]. We hypothesize that G-CSF use in premenopausal nodepositive breast cancer patients, especially in the era of induced angiogenesis, may activate and repopulate these dormant breast cancer stem cells more efficiently as well as stimulating blood stem cells. Consequently, activated breast cancer stem cells become chemosensitive to cell cycle-specific various chemotherapeutic agents.

\section{References}

1. Retsky M, Bonadonna G, Demicheli R, Folkman J, Hrushesky W, Valagussa P: Hypothesis: Induced angiogenesis after surgery in premenopausal node-positive breast cancer patients is a major underlying reason why adjuvant chemotherapy works particularly well for those patients. Breast Cancer Res 2004, 6: R372-R374.

2. Altundag K, Altundag O, Elkiran ET, Cengiz M, Ozisik: Addition of granulocyte-colony stimulating factor (G-CSF) to adjuvant treatment may increase survival in patients with operable breast cancer: interaction of G-CSF with dormant micrometastatic breast cancer cells. Med Hypotheses 2004, in press.

\section{Competing interests}

None declared. 